\title{
JFB - Trends in food bioactives
}

\author{
Fereidoon Shahidi ${ }^{\mathrm{a}^{*}}$ and Adriano Costa de Camargo ${ }^{\mathrm{b}}$
}

\begin{abstract}
aDepartment of Biochemistry, Memorial University of Newfoundland, St. John's, NL, Canada A1B 3X9
bepartamento de Ciencias Vegetales, Facultad de Agronomía e Ingeniería Forestal, Pontificia Universidad Católica de Chile, Casilla 30622, Santiago, Chile

*Corresponding author: Fereidoon Shahidi, Department of Biochemistry, Memorial University of Newfoundland, St. John's, NL, Canada A1B 3X9. Fax: +1 (709) 864- 2422; Tel: +1 (709) 864-8552; E-mail: fshahidi@mun.ca
\end{abstract}

DOI: $10.31665 /$ JFB. 2019.8203

Received: December 10, 2019; Revised received \& accepted: December 20, 2019

Citation: Shahidi, F., and de Camargo, A.C. (2019). JFB—Trends in food bioactives. J. Food Bioact. 8: 2-5.

\begin{abstract}
Food bioactives are important components found in (functional) foods and are responsible for (perceived) health benefits to human health, either as such or their metabolites. The Journal of Food Bioactives had its second year successfully reporting on different aspects of functional food ingredients in 4 volumes and, as such, captured the attention of those in the field. This report provides a cursory account of selected examples to illustrate this fact.
\end{abstract}

Keywords: Cannabis; Tea; Food By-products; Date palm; Guarana; Millet; Food Regulation.

\section{The Journal of Food Bioactives in completion of its second year}

Journal of Food Bioactives (JFB), the official journal of the International Society for Nutraceuticals and Functional Foods (ISNFF), has successfully published four volumes in 2019. However, this text does not include comments about articles appearing in volume 8 as the number of downloads was the criterion used in the selection. ISNFF and JFB are committed to bringing cutting edge research and development in the area of functional foods and bioactive ingredients and suggesting future trends to its associates and readers. Since the year 2020 is just around the corner, it is important and timely to acknowledge the authors that have submitted their contributions to the JFB.

We are proud of the high quality of all manuscripts published, and a short retrospective on the readers' interest is provided here. However, one should bear in mind that the selection of the papers mentioned is purely based upon the number of downloads (Table 1 ), thus not necessarily representing any other opinion of the editorial board. One paper from each section/volume was selected (e.g. viewpoint/perspective/opinion; review; original paper). We trust that this summary will shed some light on the topics of interest and will guide authors in the upcoming year.

The $4^{\text {th }}$ volume was published in December 2018. Therefore, its output in terms of interest was included in this report. According to Holbrook and Kani (2018), consumer perception of cannabis was largely framed by its stigma surrounding drug use. The authors also emphasized that the overall concern of rapid expansion of a massive new market of cannabinoid-containing foods and drinks is that producers/suppliers have an awareness and education in the pleiotropic physiological effects of the endocannabinoid system, are trained in safe product processing/manufacturing practices, and do not make unsubstantiated claims for health benefits without clear evidence. The bioaccessibility and bioavailability of phenolic compounds were addressed by Shahidi and Peng (2018). According to them, several works on bioavailability and physiological activity of the prevalent natural or synthetic phenolic standards/ mixtures have been carried out, but due to the diversity of phenolics and personal variations, there is still a need for a more clear and thorough understanding of the specific patterns of phenolic bioavailability. Finally, more efforts are also in progress. Thus a number of bioavailability studies covering phenolic digestion, absorption, transport, metabolism, colonic catabolism, excretion, and physiological effects are still in need of further clarification and elaboration. The original paper by Liu et al. (2018) brings about the anti-glycation effects of several natural dietary anthraquinone derivatives (e.g., aloin, aloe-emodin, chrysophanol, emodin, physcion, and rhein). The glycation of human serum albumin (HSA) plays a critical role in the development of many disorders. Their findings suggest that the anti-glycation effects of these anthraquinones may be attributed to their binding capacity and stabilization of the HSA protein structure.

In the $1^{\text {st }}$ volume of $2019, \mathrm{Li}$ and co-workers have used tea ex- 
Table 1. Most downloaded articles from 2019

\begin{tabular}{|c|c|c|}
\hline Section & Title & Keywords \\
\hline \multicolumn{3}{|l|}{ Volume 7} \\
\hline Perspective & $\begin{array}{l}\text { A perspective on phenolic compounds, their potential } \\
\text { health benefits, and international regulations: The } \\
\text { revised Brazilian normative on food supplements }\end{array}$ & $\begin{array}{l}\text { Normative Instruction (NI) N²8; Proanthocyanidins; } \\
\text { Tocopherols; Brazil; Polyphenols }\end{array}$ \\
\hline Review & $\begin{array}{l}\text { Anticancer and antiproliferative properties of food- } \\
\text { derived protein hydrolysates and peptides }\end{array}$ & $\begin{array}{l}\text { Antitumor; Lunasin; Cancer; Apoptosis; } \\
\text { Bioactive peptides; Antiproliferative }\end{array}$ \\
\hline Original & $\begin{array}{l}\text { Revisiting DPPH (2,2-diphenyl-1-picrylhydrazyl) } \\
\text { assay as a useful tool in antioxidant evaluation: A } \\
\text { new IC100 concept to address its limitations }\end{array}$ & $\begin{array}{l}\mathrm{IC}_{100} \text {; DPPH; Radical scavenging ability; } \\
\text { Stoichiometric factor; Antioxidant capacity }\end{array}$ \\
\hline \multicolumn{3}{|l|}{ Volume 6} \\
\hline Opinion & Guarana as a source of bioactive compounds & $\begin{array}{l}\text { Caffeine; Phenolic compounds; Antioxidant properties; } \\
\text { Anti-Inflammatory potential; Antimicrobial activity }\end{array}$ \\
\hline Review & $\begin{array}{l}\text { Utilization of marine by-products for the } \\
\text { recovery of value-added products }\end{array}$ & $\begin{array}{l}\text { Fish; Shellfish; By-products; By-catch; Discards; } \\
\text { Processing; Added-value; Nutraceutical; } \\
\text { Omega-3 oil; Biopeptide; Chitosan }\end{array}$ \\
\hline Original & $\begin{array}{l}\text { Bioaccessibility and antioxidant activities } \\
\text { of finger millet food phenolics }\end{array}$ & $\begin{array}{l}\text { Colonic fermentation; Cooking methods; } \\
\text { Dynamic in vitro digestion; Retentate }\end{array}$ \\
\hline \multicolumn{3}{|l|}{ Volume 5} \\
\hline Viewpoint & $\begin{array}{l}\text { Profiled tea extracts exemplifying the importance } \\
\text { of characterizing food bioactives: opinion piece }\end{array}$ & $\begin{array}{l}\text { Characterization; Natural product; Tea biological } \\
\text { activity; Food bioactives; Phytochemical profile }\end{array}$ \\
\hline Review & $\begin{array}{l}\text { Phenolic compounds in agri-food by-products, } \\
\text { their bioavailability and health effects }\end{array}$ & $\begin{array}{l}\text { By-products; Bioactive compounds; Phenolics; } \\
\text { Nutraceuticals; Health benefits; Bioavailability }\end{array}$ \\
\hline Original & $\begin{array}{l}\text { Phenolic content, antioxidant and anti-inflammatory activities } \\
\text { of seeds and leaves of date palm (Phoenix dactylifera L.) }\end{array}$ & $\begin{array}{l}\text { Date seeds; Leaves; Antioxidant activity; Phenolic profile; } \\
\text { DNA breakdown inhibition; LDL oxidation inhibition }\end{array}$ \\
\hline \multicolumn{3}{|l|}{ Volume 4} \\
\hline Opinion & $\begin{array}{l}\text { Cannabis infused foods and drinks: Food } \\
\text { safety and the endocannabinoid system }\end{array}$ & Endocannabinoid system; Cannabis edibles; CBD oils \\
\hline Review & Bioaccessibility and bioavailability of phenolic compounds & $\begin{array}{l}\text { Phenolics; Bioavailability; Transporters; In } \\
\text { vivo metabolism; Colonic catabolism }\end{array}$ \\
\hline Original & $\begin{array}{l}\text { Bioactive anthraquinones found in plant foods } \\
\text { interact with human serum albumin and inhibit the } \\
\text { formation of advanced glycation endproducts }\end{array}$ & $\begin{array}{l}\text { Anthraquinone; Rhein; Advanced glycation endproducts } \\
\text { (AGEs); Human serum albumin (HSA); Circular } \\
\text { dichroism (CD); Isothermal titration calorimetry (ITC) }\end{array}$ \\
\hline
\end{tabular}

tracts to exemplify the importance of characterizing food bioactives. According to them, natural products from food and herbs have been used as functional foods and medicines for centuries, much earlier than any of the current single molecule or drugs in the market. Historically, natural products are the dominant resources of the current global pharmaceutical market. However, the importance of the phytochemical characterization of plant origin and associated extracts containing multiple phytochemicals in research and product development in this field has been plagued by overwhelmingly focusing on their biological effects. Hence it is vital to characterize and identify the ingredients in the plant extractsfood bioactive compounds - that play critical roles in promoting health or having therapeutic effects. The combination of chemical identification and biological evaluation is the key to having valid and consistent results in elucidating health-beneficial properties of a plant or its extracts and also a key to having a meaningful comparison among similar studies due to the use of the same standard. Phenolic compounds in plant-based foods may render a myriad of beneficial health effects, including prevention of cancer, cardiovascular disease, diabetes, immune disorders, neurogenerative disease, and others. Shahidi et al. (2019a) revised several studies and summarized the occurrence of phenolic compounds and some other bioactives in various agri-food by-products from fruits, vegetables, tree nuts, legumes, cereals, oil seeds, beverages, as well as their bioavailability and health benefits. The authors also briefly addressed the presence of other bioactive compounds (e.g., carotenoids and betalains). The total phenolic content of date palm (Phoenix dactylifera L.) seeds and leaves were determined and, for the first time, their antioxidant activity in a food system investigated by John and Shahidi (2019). A number of phenolic compounds including proanthocyanidin dimers, catechin, epicatechin, 5-O-caffeoylshikimic acid isomers, ferulic acid, rutin, and isorhamnetin hexoside, among others, were detected in date palm seeds and leaves. Due to their inhibition capacity towards cupric ion-induced human LDL-cholesterol peroxidation and supercoiled plasmid DNA strand scission inhibition, it is possible to suggest that phenolic compounds date palm seeds and leaves could potentially prevent cardiovascular diseases and mutagenesis. Finally, their data also supports the use of date palm seeds or leaves as a natural source of anti-inflammatory substances. 


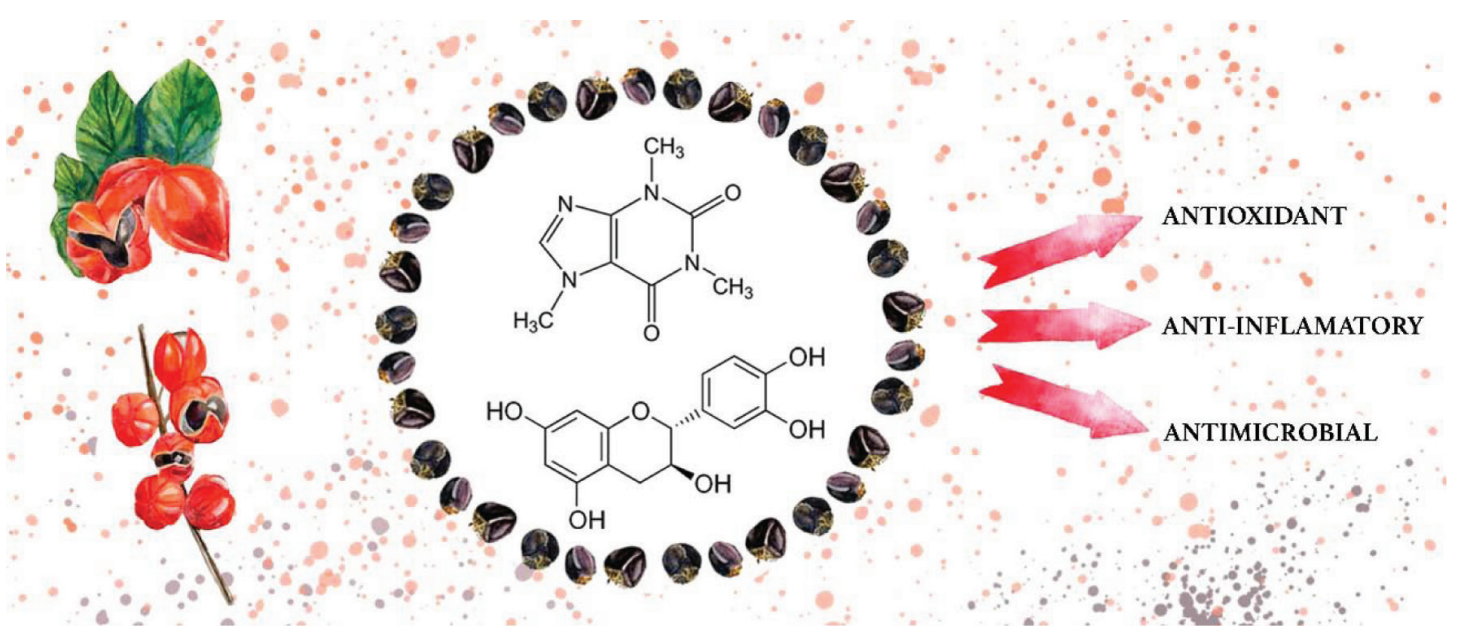

Figure 1. Guarana as a source of bioactive compounds (Silva et al. 2019).

Guarana as a source of bioactive compounds (Silva et al., 2019), an opinion article, was chosen as the cover of the $6^{\text {th }}$ volume (Figure 1). According to their report, guarana has been listed in the Brazilian Pharmacopoeia and is also introduced in the U.S. Pharmacopeia, under monographs for guarana seed, its powder, and dry extract. The Brazilian Food Supplement Law recently recognized that guarana presents bioactive substances, hence supporting its role as a functional food ingredient. The authors concluded that the potential health benefits of guarana go beyond the action of caffeine. Prevention of cardiovascular diseases and benefits on cognitive performance related to phenolics from guarana have been reported. Besides that, due to their inhibitory effect towards $\alpha$-glucosidase and $\alpha$-amylase, its promising action as a new antihyperglycemic agent for prevention and/or management of type 2 diabetes has been highlighted. However, to confirm the benefits of guarana in humans, this evidence must be further addressed in clinical trials. The world fisheries resources have exceeded 160 million tons in recent years. However, every year a considerable amount of total catch is discarded as by-catch or as processing leftovers, and that includes trimmings, fins, frames, heads, skin, viscera, among others. Accordingly, the utilization of marine byproducts for the recovery of value-added products was addressed in Shahidi et al. (2019b). The characteristics and utilization of the main ingredients such as protein, lipid, chitin and its derivatives, enzymes, carotenoids, and minerals originating from marine byproducts was covered in the mentioned contribution. Supporting the trend raised by the paper by Shahidi and Peng (2018), the manuscript entitled "Bioaccessibility and antioxidant activities of finger millet food phenolics" by Kumari et al. (2019) was the most accessed original article from the $6^{\text {th }}$ volume. Finger millet flour, which is widely used in the African continent and the Indian subcontinent, was used to prepare five different foods using steaming, pressure cooking, dry roasting, and open boiling as representative preparation methods. The authors concluded that different cooking methods affect the phenolic contents and antioxidant activities of finger millet foods. The release of phenolic compounds increased stepwise from gastric to intestinal phase for all finger millet foods and their bioaccessibility and potential absorption depended on different food preparation methods. The released phenolic compounds and their antioxidant activities at each phase of digestion of finger millet showed the potential ability to protect human gastrointestinal tract from conditions related to oxidative stress. Generally, finger millet thin and thick porridges prepared by open boiling showed more absorbable phenolic compounds and high potential to provide postprandial antioxidant activities compared to other food preparation methods used.

Food regulation was the main subject of the perspective paper entitled "A perspective on phenolic compounds, their potential health benefits, and international regulations: The revised Brazilian normative on food supplements" by de Camargo and Lima (2019). According to them, Anvisa, Brazil's national regulatory body, has recently revised the regulation on food supplements and only a few phenolic compounds (chlorogenic acid, rutin, proanthocyanidins, and tocopherols) have been mentioned. Despite several scientific evidences on the bioactivity of phenolics, especially concerning their antioxidant activity, Anvisa does not authorize any claims for supplements containing these compounds, except for alpha-tocopherol, which was mentioned as "vitamin E". In summary, more clinical trials are needed in order to study aspects related to the bioavailability and bioactivity of different groups of polyphenols, which would help advance the current level of health claims approved in the regulation. Additionally, claims related to the antioxidant action and/or free radical scavenging activity of monophenols (e.g., tocopherols) should be extended to compounds such as chlorogenic acid, rutin, and proanthocyanidins. Finally, Brazilian sources of these compounds should be included. Cancers of all types are among the four main non-communicable diseases, a category of diseases responsible for 38 million yearly deaths worldwide (Nwachukwu and Aluko, 2019). The authors summarized the various methods used for producing anticancer peptides and protein hydrolysates from food sources, their modes of action, as well as descriptions of their antitumor properties in cellular and animal models. The mechanisms by which protein hydrolysates and peptides exert their antitumor and antiproliferative effects have not been entirely elucidated. However, there is evidence pointing to the important role of their antioxidative function. Accordingly, the authors concluded that future studies should focus on the prospect of utilizing antioxidant bioactive peptides in cancer combination therapy. Amongst the original articles, a paper related to the analytical methods (Yeo and Shahidi, 2019) was the most accessed one in the $7^{\text {th }}$ volume. The DPPH (2,2-diphenyl-1-picrylhydrazyl) assay has been widely used in antioxidant evaluation. However, it suffers from certain limitations that are addressed in their contribution. The modified $\mathrm{DPPH}$ assay proposes a new concept, $\mathrm{IC}_{100}$, that is defined as the amount of DPPH radical required to oxidize all antioxidants pre- 
sent in the reaction medium. The modified DPPH assay does not suffer from an underestimation of antioxidant activity found in the original DPPH procedure due to the decrease in the ratio of DPPH radicals to antioxidants. Moreover, the modified method was not influenced by interference from coexisting pigments in the measurement of radical scavenging potential of extracts. This was the first attempt to effectively resolve the above-mentioned limitations of the DPPH assay.

\section{Concluding remarks and future trends}

Despite the fact that some phenolic and other bioactive compounds have been regarded as poorly absorbed, recent advances will provide evidence of their absorption as such or their metabolites. The omics as well as microbiome approach and the effect of gut microbiota will continue to shed light on different aspects of research and development in this field. The regulations governing functional foods, nutraceuticals, and dietary supplements is also expected to be further developed and hopefully enforced.

\section{References}

de Camargo, A.C., and Lima, R.S. (2019). A perspective on phenolic compounds, their potential health benefits, and international regulations: The revised Brazilian normative on food supplements. J. Food Bioact. 7: 7-17.

Holbrook, L., and Kani, M. (2018). Cannabis infused foods and drinks: Food safety and the endocannabinoid system. J. Food Bioact. 4: 8-10.

John, J.A., and Shahidi, F. (2019). Phenolic content, antioxidant and antiinflammatory activities of seeds and leaves of date palm (Phoenix dactylifera L.). J. Food Bioact. 5: 120-130.

Kumari, D., Chandrasekara, A., and Shahidi, F. (2019). Bioaccessibility and antioxidant activities of finger millet food phenolics. J. Food Bioact. 6: 100-109.

Li, S., Gosslau, A., Lange, K., and Ho, C.-T. (2019). Profiled tea extracts exemplifying the importance of characterizing food bioactives: opinion piece. J. Food Bioact. 5: 1-5.

Liu, W., Cai, A., Carley, R., Rocchio, R., Petrovas, Z.M., Chartier, C.A., Meng, X., Su, J., Cho, B.P., Dain, J.A., Ma, H., and Seeram, N.P. (2018). Bioactive anthraquinones found in plant foods interact with human serum albumin and inhibit the formation of advanced glycation endproducts. J. Food Bioact. 4: 130-138.

Nwachukwu, I.D., and Aluko, R.E. (2019). Anticancer and antiproliferative properties of food-derived protein hydrolysates and peptides. J. Food Bioact. 7: 18-26.

Shahidi, F., and Peng, H. (2018). Bioaccessibility and bioavailability of phenolic compounds. J. Food Bioact. 4: 11-68.

Shahidi, F., Varatharajan, V., Oh, W.Y., and Peng, H. (2019a). Phenolic compounds in agri-food by-products, their bioavailability and health effects. J. Food Bioact. 5: 57-119.

Shahidi, F., Varatharajan, V., Peng, H., and Senadheera, R. (2019b). Utilization of marine by-products for the recovery of value-added products. J. Food Bioact. 6: 10-61.

Silva, C.P, Soares-Freitas, R.A.M., Sampaio, G.R., de Camargo, A.C., and Torres, E.A.F.S. (2019). Guarana as a source of bioactive compounds. J. Food Bioact. 6: 1-5.

Yeo, J., and Shahidi, F. (2019). Revisiting DPPH (2,2-diphenyl-1-picrylhydrazyl) assay as a useful tool in antioxidant evaluation: $\mathrm{A}$ new $\mathrm{IC}_{100}$ concept to address its limitations. J. Food Bioact. 7: 36-42. 